\title{
COMUNICACIÓN EN EL AULA REPRODUCE INEQUIDAD
}

\author{
M.Sc. Ana Lucía Villarreal Montoya
}

\begin{abstract}
Resumen: En este artículo se presentan algunos resultados de la investigación "Comportamiento comunicacional de hombres y mujeres en los procesos educativos", la cual se propuso visibilizar cómo se operacionaliza la comunicación en los procesos educativos y cómo reproduce las inequidades características de una sociedad patriarcal. Para lograrlo se analiza la comunicación desde tres aspectos: lenguaje, relaciones y espacio; empleando metodología cualitativa y técnicas de investigación como la observación de un curso semestral a nivel de licenciatura, entrevista a sujet@s de los procesos educativos y revisión y análisis de documentos.
\end{abstract}

Descriptores: EDUCACIÓN Y GÉNERO/ ESPACIO EN LA EDUCACIÓN/ COMUNICACIÓN Y EDUCACIÓN/ RELACIONES DE PODER EN LA EDUCACIÓN/ LENGUAJE SEXISTA

\begin{abstract}
In this article are display some of the results of the investigation "Communicational behavior of men and women in the educative processes". That propose to observate how executes the communication in the educative processes and how reproduce the unfairness characteristics of a patriarchal society. To reach it, the communication it's analize from tree aspectes: language, relationships and space; using cualitative metodology and techniques as the observation of a degree semestral course, interview of subjects of the educative processes, overhaul and analysis of documents.
\end{abstract}

Key words: EDUCATION AND GENDER/ SPACE IN THE EDUCATION/ COMMUNICATION AND EDUCATION/ RELATIONS TO BE ABLE IN THE EDUCATION/ LANGUAGE SEXISTA

\section{Presentación}

Al inscribirse en la perspectiva de género esta investigación se propuso observar los procesos educativos con un lente diferente al que estamos acostumbrados a utilizar para mirarlos, por lo que los datos que se obtienen del proceso investigativo deben entenderse y tratar de leerse con ese otro lente.

\footnotetext{
1 Maestría en Sociología, bachillerato y licenciatura en Ciencias de la Comunicación, todos de la Universidad de Costa Rica. Docente de la Escuela de Ciencias de la Comunicación e investigadora del Instituto de Investigaciones para el Mejoramiento de la Educación Costarricense, ambos de la Universidad de Costa Rica (UCR). Tutora de la Escuela de Ciencias Exactas y profesora de la Maestría en Estudios de la Violencia Social y Familiar, ambas de la Universidad Estatal a Distancia (UNED). Relacionista pública. comunicadora agrícola y periodista. e-mail: avillarr@cariari.ucr.ac.cl
}

Artículo recibido: 8 de octubre, 2003

Aprobado: 24 de noviembre, 2003 
Con lo anterior se invita a la lectora y al lector de este artículo a arriesgarse a hacer la lectura desde ese otro lente, con lo cual también se les invita a arriesgarse a emplear los datos que se aportan a continuación como un espejo, en el cual nos podemos mirar nosotr@\$mism@s como docentes, estudiantes u autoridades educativas. Ya que de lo contrario asumiremos una de las conductas aprendidas y que nos impiden avanzar en el camino de la construcción de una sociedad equitativa para las personas, la conducta de juzgar el accionar del otro y de la otra como bueno o malo, no como producto del contexto y sociedad patriarcal en que vivimos; conducta que nos impide vernos en el otro u otra y por lo tanto conocernos mejor.

\section{Premisas de investigación:}

Las premisas de que parte la investigación (desarrolladas en el marco conceptual de la misma) son las siguientes:

- Esta investigación se inscribe dentro del paradigma de desarrollo humano.

- La comunicación se concreta en el aula en tres aspectos: lenguaje, relaciones y espacio.

- Las relaciones de poder patriarcales dominación/subordinación se reproducen en el aula:

- Invisibilización de las mujeres: la mayor violencia del patriarcado hacia el genero femenino.

- Cada modelo de educación tiene implícito un modelo de comunicación y un_modelo espacial

- Programad@s pero no determinad@s

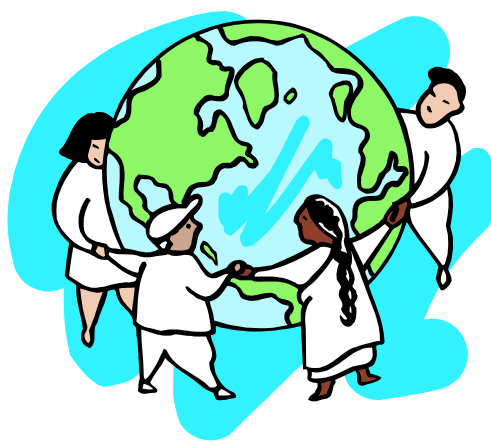

\footnotetext{
${ }^{2}$ Se adopta el uso del símbolo @ como una forma de visibilizar el problema no resuelto del uso del
} genérico "hombre" en el lenguaje. 


\section{DATOS QUE PERMITEN CONSTRUIR EL CAMBIO}

A pesar de las diferentes propuestas surgidas en el campo de la educación, tendientes a superar procesos educativos enfatizados en el aprendizaje de contenidos, entre las cuales se encuentran la educación holista (Gallegos, 1999), el constructivismo (Coll, Martín y otros, 1997), pedagogía de la esperanza (Freire, 1998) y otras; los proceso educativos mantienen un marcado acento en contenidos y con ello se reproducen procesos comunicativos entre un o una emisora (docente, quien sabe) y un o una perceptora (estudiante, quien aprende, porque no sabe).

Esta es una de las constataciones que se hizo como parte del proyecto de investigación "Comportamiento comunicativo de hombres y mujeres en el proceso educativo", realizado durante los años 2001 y 2002, en el Programa de Investigación en Educación y Género (PIEG) del Instituto de Investigaciones para el Mejoramiento de la Educación Costarricense (IIMEC).

Los comportamientos comunicacionales de I@s actor@s de los procesos educativos se desarrollan en el marco de relaciones de poder dominación/subordinación o del sistema sexo-génerd ${ }^{5}$ vigente, lo cual implica que se circunscriben dentro de los modelos llamados por Días Bordenabe (Kaplún, 1985, p. 17) con énfasis en el conocimiento y con énfasis en los efectos.

Por lo cual la estructura de la sociedad patriarcal programa a los seres humanos para asumir de una forma no consciente conductas agresivas/sumisas, dominantes/subordinadas, pero a pesar de que estamos programados no estamos determinados, como lo retoma Freire (1998, p. 94) “... aunque 'programados', no estamos sin embargo determinados; es por estar siendo así por lo que hemos venido desarrollando la vocación para la humanización y que tenemos en la deshumanización, hecho concreto en la historia, la distorsión de la vocación".

El objetivo de la investigación consistió en analizar y visibilizar cómo se comunican y relacionan las y los actores del proceso educativo, según su sexo/género, en el aula; según el sexo biológico y según el género, entendido como una construcción y producto social. Así

${ }^{3}$ Se entiende por sistema sexo-género al que contiene al sexo como un dato biológico y al género como un dato social y cultural (Abromovay, 1994, p. 13)." Al sistema sexo-género con dominación masculina se le llama también patriarcado" (Miranda, 1994, p. 49). 
como visibilizar cómo los tipos de comunicación/relaciones que se establecen en los diferentes momentos y actividades del proceso educativo, juegan un papel determinante en éstos, ya que la comunicación es una de las herramientas que operacionaliza la propuesta de modelo educativo implícita o explícita en los programas educativos.

Se estudia la comunicación ya que “... por el modo particular según el cual realiza su función técnica de comunicación, un sistema escolar determinado realiza además su función social de conservación y su función ideológica de legitimación” (Bourdieu, 1970, p. 154)

La investigación de campo se llevó a cabo en un curso licenciatura de la Escuela de Administración Educativa, de la Facultad de Educación de la Universidad de Costa Rica, durante el primer semestre del 2002; proceso que fue posible gracias al apoyo de la docente del curso de una manera desinteresada y comprometida con la construcción de la equidad de género en la educación.

También se realizaron entrevistas a la docente y a cuatro estudiantes (dos mujeres y dos hombres), así como se analizó \&\& el sexismo en el lenguaje empleado en documentos, como el programa del curso. En el curso observado el número de estudiantes por sexo es el siguiente: 7 mujeres y 4 hombres, una mujer no concluyó.

Para complementar el análisis se le solicitó -en marzo del 2002- al Ing. Warner Carvajal, jefe de la Oficina de Registro e Información (ORI) de la Universidad de Costa Rica, las estadísticas de la Facultad de Educación, ordenada por sexo, de las y los estudiantes para los períodos 1995 y 2001.

Estas estadísticas aportan los siguientes datos:

Fuente: Unidad de Matrícula, ORI; Marzo 2002.

\begin{tabular}{|c|c|c|}
\hline Año & Mujeres & Hombres \\
\hline $1995(\mathrm{a})$ & 3141 & 1102 \\
\hline $2001(\mathrm{~b})$ & 2718 & 1211 \\
\hline
\end{tabular}

(a) Al 19 de enero de 1995 .

(b) Al 20 de abril del 2001 
Datos que muestran claramente que del total de estudiantes de la Facultad de Educación la mayoría son mujeres, en ambos periodos el número de estudiantes mujeres supera el 70 por ciento, en relación con los varones. Sin embargo, los documentos (perfiles, programas de curso) están escritos en masculino, con lo cual se invisibiliza a las estudiantes y sobre todo se enseña a las y los futuros docentes de todos los niveles educativos que esta es la forma "correcta" de elaborar estos documentos y con ello se contribuye a mantener el patriarcado y sus reglas del juego.

A continuación se exponen los resultados obtenidos del proceso investigativo en cada uno de los tres aspectos que se concreta la comunicación en el proceso educativo: lenguaje, comunicación/relaciones y uso del espacio.

\section{LENGUAJE}

Sobre este tema existen múltiples investigaciones y construcciones teórico metodológicas, algunas de las cuales se retoman en este trabajo. María Ángeles Calero (1999, p. 9) afirma que en las sociedades patriarcales los sistemas lingüísticos presentan una marcada óptica masculina, es lo que se llama androcentrismo, el cual acarrea, la infravaloración y hasta la ocultación de lo femenino y puede ir acompañado, además, de un componente misógeno.

Ejemplos del sexismo en el lenguaje se observan en documentos producidos para el proceso educativo: perfil profesional, programas de los cursos; en la escogencia de la bibliografía. Casi todos estos materiales están escritos utilizando el masculino como genérico, sin tomar en cuenta los porcentajes de mujeres y hombres (docentes y estudiantes) que participan en los procesos educativos.

No obstante lo anterior, en el caso de la Escuela de Administración Educativa se visibilizó a las mujeres en el programa de la VIII celebración del día de este gremio, al mencionarse en dicho documento (noviembre, 2002) "VIII CELEBRACIÓN DEL DÍA DE LOS Y LAS PROFESIONALES DE LA ADMINISTRACIÓN EDUCATIVA". 


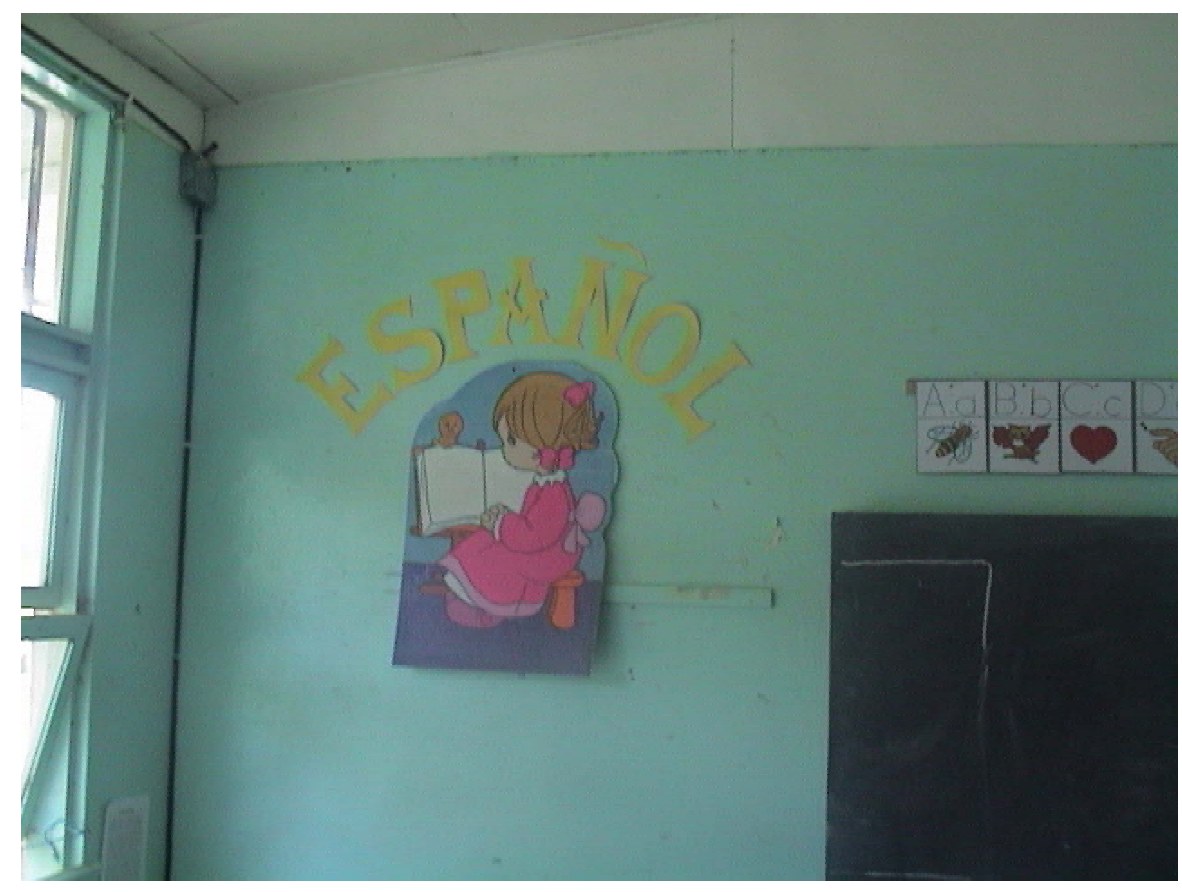

\subsection{Lenguaje como fondo colectivo común}

Se analiza la lengua como fondo colectivo común, porque como se ha afirmado esta también representa un rol en las relaciones de poder y en los procesos de valorización social, de manera que ciertos usos, percibidos como característicos de los grupos dominantes, son más apreciados y tienden a ser adoptados por las otras capas sociales (Vásquez, 1996, p. 58).

a) Uso del genérico 'hombre':

En la primera clase la profesora utilizó el genérico para referirse a hombre y mujer. Por ejemplo dijo:

- "La teoría administrativa surge cuando surgen esos grandes hombres, Taylor y Fayol ¿quiénes de ustedes no han oído hablar de esos grandes hombres?"

- Todos ustedes tienen como meta ser directores de centros educativos o de proyectos.

- Nosotros como administradores.

- Un administrador es como un gerente.

También en algunas ocasiones -en las menos- empleó términos en ambos géneros:

- La diferencia entre administrador y administradora educativa es ...

- Compañeros y compañeras.

- Ustedes están estudiando para ser administradores y administradoras de la educación. 
Y acepta la dificultad del empleo de un lenguaje no sexista al expresar "A mi me cuesta decir administrador/administradora, entonces 'una persona que administra una organización' ".

Desde la primera clase se plantea el tema de género cuando una estudiante dice "Los directores regionales por lo general son hombres ¿cuántas mujeres conocen como directoras regionales? yo no conozco ninguna. Es un problema de género". A lo cual la profesora responde: "Sí ellos tienen un gran poder"; acepta tal situación como 'normal'.

El texto que se utilizó en el curso observado emplea el término "hombre" como genérico de hombre y mujer. Aspecto que tuvo diferentes incidencias en el curso.

- La profesora cuando leía partes del texto y cuando aparecía esta palabra simplemente la leía, no visibilizaba esta situación, ni tampoco asumía una actitud de equidad, lo cual podría haber llevado a cabo de varias formas: visibilizando el hecho, proponiendo diversas formas de superar esta situación, que el grupo decidiera cuál emplear. Entre esas formas están: agregando al hombre "y la mujer", o variando la palabra por "persona" o "ser humano".

- Ante este comportamiento una de las estudiantes visibiliza el hecho y pregunta que por qué se utiliza la palabra "hombre" como genérico. Esta pregunta no fue ni respondida ni comentada por ninguna de las personas presentes (profesora y estudiantes de ambos sexos).

- En una clase de abril, uno de los hombres de la clase comentó a la profesora acerca del lenguaje de género y de la necesidad de decir "los y las" para incluir a las mujeres. La profesora respondió que eso es complicado. En esa misma clase una estudiante comentó acerca de la disposición de la Real Academia de decir "las compañeras" incluyendo así a los varones, cuando ellas son mayoría, comentario que no fue comentado por la docente, ni por sus compañer@s.

Como vemos, la docente responde al comentario sobre el sexismo en el lenguaje cuando quien lo hace es un hombre y hace un comentario reafirmante, mientras que no responde cuando quienes plantean el cuestionamiento son mujeres. 
Esta situación llamó la atención de la investigadora, por lo cual fue retomada en las entrevistas a las y los estudiantes, consultándoles su opinión a la reacción de la profesora y de sus compañer@s; las respuestas fueron las siguientes:

"Yo creo personalmente que la lucha que ella está haciendo está bien, pero no comparto la forma en que lo está haciendo. Ella podía buscar la dirección del autor (del texto) y escribir su recomendación, a quien corresponde directamente, porque nosotros no podemos hacer ningún cambio" (Hombre 1).

Un educador que dice ser consciente del sexismo en el lenguaje expresa que el aula no es la forma para visibilizarlo y cambiar esta situación.

Tanto el Hombre 1 como la Mujer 1 entrevistad@s coinciden en que la forma en que su compañera se refirió al tema tenía intenciones diferentes a la obtención de la equidad, dan a entender que lo que ella quería era figurar o llamar la atención:

"En parte no es tanto por la cuestión de género. Siento que es por el afán de ella de sobresalir. Ella defiende esa posición de que es mujer y tiene derechos y todo debe ser igual" (Mujer 1).

Las otras dos personas entrevistadas expresaron al respecto:

"La gente acepta como normal que se use el genérico. Podría cambiarse la palabra por persona, pero poco a poco" (Hombre 2).

"Como que a nadie le interesó el tema. Se ve como algo aislado" (Mujer 2).

Se debe destacar cómo en estas respuestas están implícitos varios aspectos que es importante visibilizar:

- el hecho de que el hacer uso de la palabra implica un asunto de poder, "ella quería llamar la atención", "no comparto la forma en que lo está haciendo" (poniéndose de pie y hablando en forma agresiva);

- el que una mujer utilice la palabra para defender sus derechos es cuestionado por hombres y mujeres, pero no se cuestiona el que por cientos de años los hombres utilicen 
la palabra como herramienta para ejercer el poder y que empleen el genérico; con lo cual se acepta como correcta la violencia por omisión en el lenguaje.

“(Las compañeras) creen que esa no es la forma, no imponiéndose. La forma de ella no es la mejor para hacerlo, porque no estamos en un curso de género" (Hombre 1).

b) Lenguaje no sexista atenta contra lo establecido (el poder):

El variar los textos o visibilizar la violencia por omisión es calificado como contrario a la estructura del cerebro o molesto, por los hombres entrevistados:

"Se refiere al hombre, pero en la estructura del cerebro está el hombre y la mujer (al decir hombre) y si se dice hombre y mujer esto no está en la estructura del cerebro" (Hombre 2).

Aquí este hombre expone (insconscientemente) cómo la socialización en una sociedad patriarcal hace creer a las personas sus premisas y el sólo hecho de variar el uso de "hombre" como genérico, por el uso de "el hombre y la mujer" es calificado como contrario a la estructura mental aprendida y empleada cotidianamente.

"Más pereza utilizar el y ella, más fácil usar un sólo género y seguir" (Hombre 1).

c) Pero a hombres sí les interesa su invisiblización:

Pero los hombres sí visibilizan cuando se presentan agresiones por el empleo del femenino, ya sea para desvalorizarlos o para invisibilizarlos. Por ejemplo uno de los estudiantes entrevistados llamó la atención sobre la agresión de que son objeto los hijos hombres por la madre, al descalificarlos empleando la palabra "mujercitas".

"Para mí es más humillante el uso del lenguaje que usa la madre cuando le dice a los hombres (hijos) "inútiles, mujercitas", etc; causa más delincuencia la agresión en la familia que el uso del genérico" (Hombre 2).

Tema que es retomado por su compañero entrevistado: 
"Por ejemplo en el trabajo (colegio) son mayoría mujeres y se usa el femenino (como genérico), cuando se visibiliza entonces algunas mujeres dicen "a, no nos habíamos dado cuenta" o "no se hacen sentir (los hombres)" ¿por qué tanta agresividad retenida?" (Hombre 1).

Esta es una muestra muy evidente de androcentrismo en el lenguaje, lo cual se constata en esta afirmación en varios sentidos:

- El llamar a un hombre "mujercita" es agresión contra ellos, porque el lenguaje valora los términos masculinos y desvaloriza los femeninos.

- El empleo del genérico no es violencia, "es lo normal".

- Las madres reproducen estos patrones oralmente en los procesos de crianza de sus hijos e hijas.

- Por el contrario, el empleo del femenino cuando la mayoría de las personas de un grupo son mujeres, es considerado por los hombres presentes como agresión, se sientes molestos al ser invisibilizados.

Una de las mujeres entrevistadas da un ejemplo de cómo los hombres adolescentes reclaman cuando son invisiblizados:

"Al conjugar verbos se emplea las personas: yo, tu, él. Un día yo puse yo, tu, ella y los estudiantes me preguntaron ¿por qué ella?. No les pareció y yo les dije, puede ser también ella, por qué siempre tiene que ser él?" (Mujer 1).

\subsection{El lenguaje es sexista, pero...}

a) Docente y estudiantes aceptan que el lenguaje es sexista:

- Sí claro, se trata de hacer el esfuerzo porque uno es consciente. También la documentación (en el programa, en los libros, y todavía en el perfil) se habla del administrador educativo es muy masculino. Las mismas tesis, siempre se refieren al "Administrador educativo" (Docente, mujer).

- Sí, porque uno establece códigos de acuerdo con la gente que está conversando. En un grupo sólo de hombres se chotea hacia el sexo opuesto. Cuando hay una minoría de un sexo, la temática corresponde a intereses de la mayoría y la minoría se siente invisibilizada (Hombre 1). 
- Claro que es sexista el lenguaje, porque como se habla del hombre como genérico, el hombre, el administrador, refiriéndose a los hombres y a las mujeres.

- El lenguaje general es más sexista: cuando usted dice 'Qué padre' si es bueno y 'esta madre' en sentido negativo, 'parece una vieja', el ser mujer es una ofensa en el lenguaje. La regla dice que si hay 5 elementos femeninos y uno masculino, predomina el masculino a la hora de hacer concordancia (Hombre, 2).

- Claro que sí. Hasta en gramática. Por ejemplo está el sustantivo y el adjetivo que califica al sustantivo y la regla básica es que si hay varios sustantivos femeninos y uno masculino, el adjetivo que califique a los sustantivos debe estar en género masculino (Mujer 1).

- Sí. A pesar de que se está dando cierta reivindicación y más consciencia. A veces es por tradición, uno lo tiene aprendido. A veces lo hablamos inconscientemente o porque es más fácil (Mujer 2).

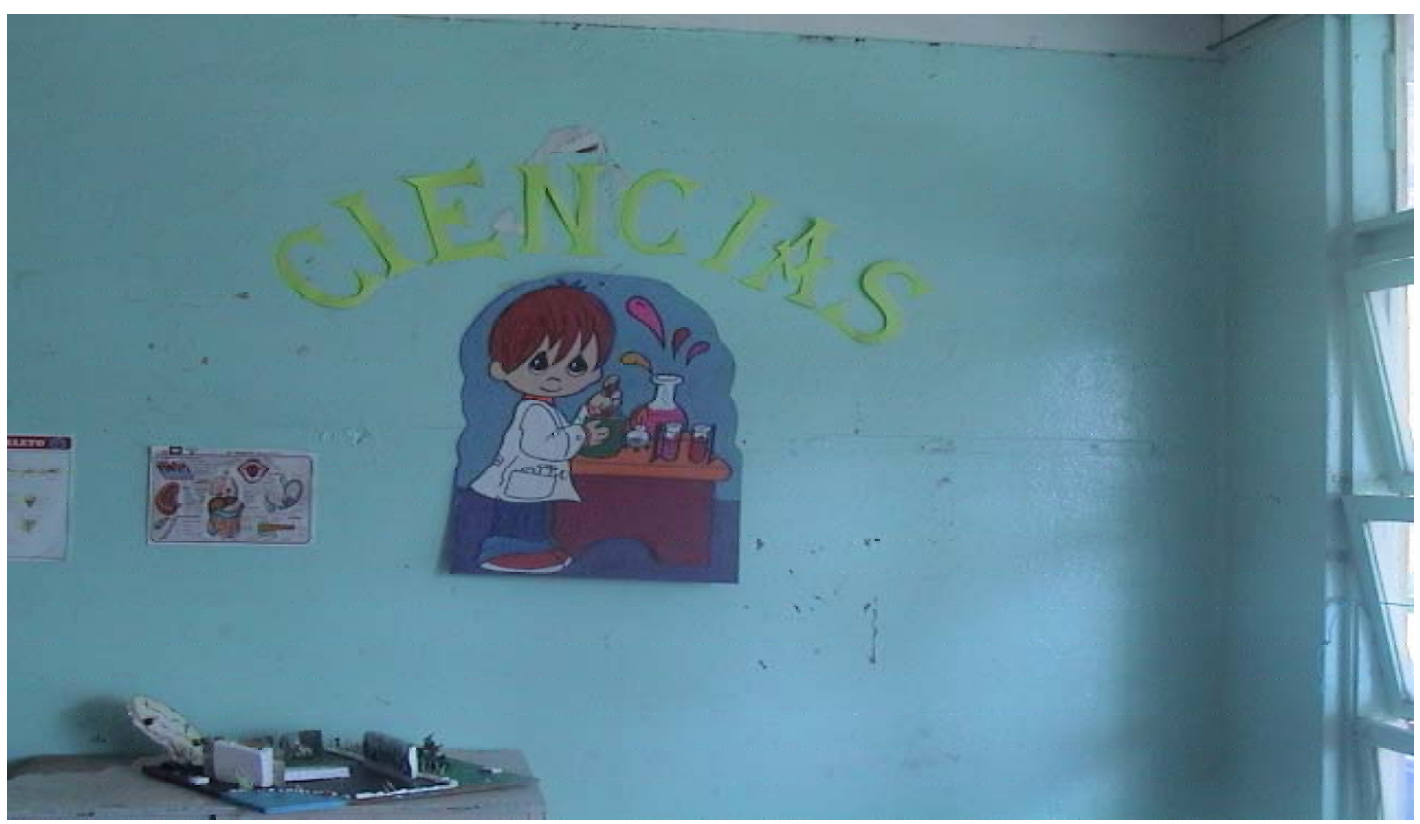

Al plantear si le prestan atención a este aspecto responden:

"Sinceramente no, porque si no se hace una confusión. A veces sí les digo 'jóvenes y jóvenas', por broma" (Hombre 2). 
Como vemos, este maestro más bien hace chota del tema con sus estudiantes, con lo cual está deslegitimando los esfuerzos que se realicen para superar este fenómeno de inequidad en el lenguaje.

"Sí, en las clases siempre hablo de todas y todas, seres humanos, personas" (Mujer 2).

"Sí claro" (Mujer 1).

No obstante la Mujer 1 en sus respuestas durante toda la entrevista se refirió a las y los estudiantes como 'ellos y chiquillos'.

b) Visiblizar a las mujeres en el lenguaje "es incómodo, difícil, enreda" o lo hacemos conscientemente y por tanto sólo cuando actuamos conscientemente:

"Al tratar de quedar bien se enreda todo (al incluir femenino y masculino). Por Ej. 'el perro es el mejor amigo del hombre', habría que decir 'el perro y la perra es el mejor amigo y amiga del hombre y de la mujer' $\mathbf{W}$ Los discursos de Figueres eran muy enredados. Lo que hay que hacer es escoger genéricos." (Hombre, 2)

"Se siente incómodo cuando se tiene que nombrar 'hombre y mujer', 'administrador y administradora'. A veces a uno se le olvida, se refiere sólo a hombres. Pero sí hay una conciencia de uno y de ellos, pero la comunicación es incómoda. También la documentación (en el programa, en los libros, y todavía en el perfil) se habla del administrador educativo, es muy masculino. Con estudiantes cuando exponen trabajos ponen la figura de un hombre" (Docente, mujer).

O la socialización nos traiciona:

"Pero como uno está acostumbrado, en momentos más fuertes (cuando hay problemas) y uno actúa como es uno, usa el genérico, pero es posible cambiar" (Mujer 2).

\footnotetext{
${ }^{4}$ Este ejemplo salió publicado en una columna en La Nación de los domingos donde se abordan problemas de lenguaje.
} 


\section{RELACIONES}

El modelo educativo observado en el curso es el que pone énfasis en los contenidos, el cual tiene implícito un concepto de comunicación/relación como sinónimo de transmisión de información.

Este modelo operacionaliza el tipo de relación que se da en el proceso, el cual se caracteriza por una relación de poder, basada en el saber, la o el docente es quien sabe; saber que le autoriza para definir los contenidos, el método y las técnicas a emplear en el proceso educativo. Y, la o el estudiante asume el rol de quien se apropia del saber, de quien enseña, lo cual coloca a esta persona en una situación de sumisión.

Esta propuesta se complementa con otras, como las de Bourdieu (1970) y de Izquierdo (1991), en relación con el rol de emisor de este modelo, el cual ya sea desempeñado por una mujer o por un hombre, mantiene la característica de dominación y con ello las relaciones de poder propias de la sociedad patriarcal.

La tendencia a reinstaurar en toda persona investida de una AuP (Autoridad Pedagógica) la relación arquetípica con el padre es tan fuerte que todo aquel que enseña, por joven que sea, tiende a ser tratado como un padre... (Bourdieu, 1970, p. 59-60)

La jerarquía de los géneros conduce al establecimiento de relaciones de dominación/subordinación entre el género masculino y el femenino, independientemente de cuál sea el sexo de las personas que ocupan los espacios sociales de género, en las relaciones de género (Izquierdo, 1991, p. 82)

Propuestas que son enriquecidas con la de Prieto (1985) de "emisor privilegiado"龷 todo lo cual nos lleva a plantear que la o el docente asumen el rol que la sociedad patriarcal les ha asignado de emisores privilegiados/autoridad pedagógica (AP) en los procesos educativos, sin incidir su sexo/género

5

Daniel Prieto define como emisor privilegiado a aquellas personas, grupos, instituciones $u$ organizaciones que tienen los recursos, las condiciones o las funciones, que les permiten crear percepciones y evaluaciones a favor o en contra de tal producto o ideología. Ejemplificando con: el padre de familia, la escuela, la iglesia, los medios de difusión colectiva. 


\subsection{Definición de comunicación}

Cuando se le pide a la docente y a las y los estudiantes entrevistados definir el concepto de comunicación, lo hacen desde la transmisión de ideas, conocimientos, emociones...

- Es la transmisión de emociones, pensamientos, sentimientos, deseos, visiones de mundo de diversas formas (Mujer 2).

- Es un proceso mediante el cual 2 seres se transmiten algo (Hombre 2).

Yendo más allá de la transmisión, hasta la realimentación ...

"No es simplemente el hecho de transmitir mensajes, sino además de transmitir, recibirlos y que yo dé una respuesta. Si hay retroalimentación. Es compartir, ideas, conocimientos, sentimientos; no sólo transmitir" (Mujer 1).

Ampliando a formas de relacionarse ...

La forma de relacionarse entre los individuos, que puede ser verbal o no verbal, utilizando diferentes medios como escrito (circulares), interpersonal, teléfono, verbal" (Docente, Mujer).

Y llegando a definir comunicación como diálogo:

"Establecer un diálogo entre 2 o más personas y que se pueda respetar lo que dice o lo que se escucha, también. Sin ningún tipo de censura” (Hombre 1).

No obstante, al concretar el rol de la comunicación en la educación, el concepto se operacionaliza como transmisión de conocimientos ...

"Transferencia de conocimientos, un modelo de hombre, un modelo de sociedad, mediante los cuales se alcanzan los fines de la educación" (Docente, Mujer).

“El rol es el de transmitir conocimientos porque están en los libros. Los profesores por lo general no conversan con los estudiantes. Se mantienen dentro de lo que está en el curriculum. Para eso usan la comunicación: para ver un tema. El docente cuando 
habla, en la mayoría de lo casos, es para reprimir o para quejarse y el estudiante por lo general debe quedarse callado y no debe ser así" (Hombre 1).

Se propone que el rol de la comunicación en educación es persuadir:

"Lo importante es que lo entiendan, o persuadir a alguien de que haga lo que uno quiera. Es convencer. En educación que la gente se convenza de los valores. La comunicación verbal influye, el muchacho ahora tiene muchas imágenes, debería de haber más imagen, pero no llevarles películas porque las asocian con entretenimiento, una mezcla" (Hombre 2).

Aunque también se plantean críticas a esta concepción ...

"No se da la comunicación como un diálogo y no se da porque por ejemplo si usted escucha a un estudiante expresar algo, el docente le dice 'cuide sus palabras', no le pregunta qué quiso decir. Debe ser dinámica, espontánea y flexible, de tú a tú, entre docente y alumno" (Hombre 1).

En esta afirmación del Hombre 1 muestra claridad en cuanto a que comunicación no es: sermonear, aconsejar, lanzar advertencias o regaños, hacer pronunciamientos, ni juzgar (Sanford, 1998).

"Debería de propiciar un clima organizacional efectivo, positivo. Para unir. No es solamente que yo como profesora me ponga al frente y diga y diga. Sino que el alumno sea capaz de dar una respuesta. Tomar una posición, decir me parece, no me parece" (Mujer 1).

Y se da el caso de una mujer que plantea que la comunicación es sinónimo de relaciones horizontales:

"Que haya una relación horizontal entre todos los que están involucrados en el proceso educativo. A pesar de que soy consciente de que eso involucra más trabajo, porque es muy fácil dictar y dictar, pero ya involucrar al padre y conocer a 30 niños es 
más cansado, porque uno se involucra más. Se ve a las personas como personas y no como simples receptores. Ya los contenidos están dados" (Mujer 2).

A pesar de la claridad de esta docente en el sentido de la necesidad de establecer relaciones horizontales, ella misma aporta el hecho de que la educación pone énfasis en los contenidos, lo cual no concuerda con relaciones de este tipo.

\subsection{La comunicación en el desarrollo del curso:}

a) Cómo fue la comunicación en el desarrollo del curso:

- Normal. Al principio era emisor y receptor (E-m->R), ni se intercambiaban los roles. Después hubo más intercambio de ideas (Hombre 1).

- Amena, poca profundidad, lecciones recargadas en el alumno (Mujer 1).

- Fue sólo a nivel académico, lo que tocaba tratar en las clases, fue muy vertical (Mujer 2).

- Regular, en el sentido de que no se manejaba muchas imágenes por medio de tecnología: montar presentaciones por medio de imágenes, de películas, conferencias (Hombre 2).

b) Efectos que tuvo la comunicación en el curso:

- Fue positiva para todos los compañeros. En la interacción e intercambio de ideas. Basado en la materia hacia la práctica cotidiana (Hombre 1).

- Demasiado teórico, poco práctico, poco provechoso. Me sentí muchas veces receptora, otras emisora, peleaba porque me dejaran hablar, un día la profesora dijo "dejemos hablar a ...". Ella cortaba la comunicación y daba por terminado el tema (Mujer 1).

- En lo académico es muy positivo, porque no nos fuimos por la tangente (Mujer 2).

- No lo hace tan provechoso como si tuviera una comunicación de más calidad, como que el mensaje llega mejor, el aprendizaje se recuerda por más tiempo, permanece más, aprendizaje más permanente (Hombre 2).

Estas respuestas nos muestran cómo para las y los entrevistados -a pesar de que son docentes- la comunicación es un elemento de poca atención en el proceso educativo y cómo las percepciones son tan diversas, así como se plantea que la comunicación es buena en tanto se transmitan los contenidos. También, se presenta la crítica al poco uso de las tecnologías en el curso. 


\subsection{Relaciones/interrelaciones:}

Aunque tradicionalmente se reduce la comunicación al lenguaje, en esta investigación se retoma la comunicación como relación e interrelación entre las personas. Reconociéndose dos tipos de interacciones: verticales y horizontales (Vásquez, 1996, p. 81).

a) Interacciones verticales: se dan en el marco de una estructura asimétrica en relación con el poder. Uno de los protagonistas (el o la docente) representa a la institución, la ley, el poder, el conocimiento y posee la autoridad; mientras que el otro protagonista (alumnado) acepta que no sabe, se encuentra en una posición de sumisión a la institución y no pone en duda a la autoridad.

Estas interacciones están ritualizadas: el/la alumn@ dispone de modelos para dirigirse al/la maestr@y los intercambios que provienen del/la maestr@ también se efectúan según un modelo; pero el/la maestr@ tiene el derecho de cambiar y de imponer nuevos modelos, siempre que permanezca dentro del marco global que estipula la institución (Vásquez, 1996, p. 81).

Desde la primer clase se fijan reglas del juego: la profesora define qué hacer y cómo, los estudiantes proponen cambios (asignar temas de trabajo individual la próxima clase) y ella no los acepta.

Los tiempos asignados a las distintas labores son definidos y variados por la docente. Ejemplos de esta afirmación:

- En una clase de abril la docente determina cuánto tiempo tienen los estudiantes para desarrollar una tarea, tiempo que se extendió varios minutos más hasta que la docente decide retomar la actividad.

- En una ocasión I@s estudiantes se organizaron para traer café y galletas, querían un recreo a media clase y compartir una merienda. Negociaron con la docente para hacer un descanso. Sin embargo, la docente no les dio descanso, por lo que se quedaron sin café.

- En otra ocasión cuando trabajaron en subgrupos la profesora preguntó que si ya habían terminado el trabajo, pero no esperó respuesta alguna e inició sus comentarios.

- En una clase la docente primero les dijo a @@s estudiantes que hicieran un solo grupo y que contaban con 15 minutos para realizar una actividad. Después decidió que era mejor que trabajaran en dos grupos y que sólo tenían 10 minutos para trabajar. 
Desde el primer día de clases se presentan interrupciones de parte de la docente hacia las y los estudiantes cuando están hablando. Por ejemplo se da trabajo en parejas para hablar sobre qué es la Administración para los estudiantes y expectativas del curso; un grupo de hombres expone, seguidamente la profesora suspende la exposición del trabajo en parejas, coloca y expone transparencia. Luego retoma ejercicio de exposición de trabajo de las y los estudiantes.

Una estudiante especifica sus percepciones en cuanto a las relaciones de la docente con I@s estudiantes según el género:

"Yo creo que tenía más diálogo con los hombres, me parece. Se aprendió el nombre de los hombres y el de las mujeres los confundía. Había más participación con los hombres. Eran más extrovertidos. Las mujeres somos más tranquilas, más pasivas, también eso influye" (Mujer 2).

Esta mujer menciona un hecho que ha sido calificado como producto de la socialización: los hombres participan más que las mujeres, y en este curso no fue la excepción, a pesar de que es parte de la Facultad de Educación, en la cual hay una clara mayoría de mujeres.

Otro elemento a tomar en cuenta al conocer las relaciones verticales en el curso es la participación o no de I@s estudiantes en el diseño y ejecución del programa del curso, así como en la forma y aspectos a evaluar.

Al consultarle a I@s estudiantes si participaron en la toma de decisiones en estos aspectos sus respuestas son negativas en todos los casos:

- No porque es la costumbre que ellos lleven un diseño de lo que van a dar y cómo lo van a hacer, lo leen y todos aceptamos (Mujer 2).

La Mujer 2 destaca uno de los ritos de la institución, que ella califica como "costumbre".

- Sólo hubo una modificación: hicimos el examen en casa, por cuestión de tiempo y todos aceptamos -la propuesta de la docente- (Mujer 2). 
- Al contrario, más bien los compañeros quisieron hacer una modificación en las comprobaciones de lectura (hacer sólo el comentario, sin el resumen) y no se aceptó (Hombre 2).

L@s cuatro estudiantes entrevistado@s concordaron en que ellos no participaron ni en el diseño del programa del curso ni en la evaluación del curso.

Estas respuestas se contradicen con la de la docente quien al consultarle si I@s estudiantes participaron respondió: En la metodología sí y en la evaluación. Usted les lleva una propuesta y se escuchan sugerencias. No es que participen en el diseño del curso.

b) Interacciones horizontales: los protagonistas de estas son pares. Son amplias: se extienden de manera flexible a través del tiempo, pueden reproducirse muchas veces a lo largo de una clase y mucho más aún; la flexibilidad le permite a los actores estar relativamente atentos a la lección al mismo tiempo que entablan interacciones entre ellos. Cuando se observa el conjunto de una clase se puede afirmar que la mayoría del tiempo hay alumn@s practicando interacciones horizontales. Aparentemente el/la maestr@ no interviene, se desarrollan a pesar suyo, lo cual probablemente les confiere una parte de su atractivo (Vásquez, 1996, p. 81).

En la observación de la primera clase se dan interacciones horizontales entre estudiantes. La profesora llama la atención a una mujer porque está hablando con otra; la estudiante le explica que está viendo si apuntó todo lo que tiene que hacer. Pocos minutos después se da otra interacción horizontal, en este caso entre dos hombres y contrario al caso anterior la docente les pregunta “¿tienen mucha energía?”.

Se observa un trato diferente para una misma conducta: cuatro personas (dos hombres y dos mujeres) interrumpen la clase al hablar, la docente llama la atención a las mujeres, mientras que a los hombres les califica el hecho como exceso de energía.

Al consultarle a I@s entrevistad@s sobre las relaciones con sus compañeras y compañeras, haciendo la diferencia por sexo/género, los hombres responden que son buenas -tanto con los compañeros como con las compañeras; no obstante las mujeres 
hacen una distinción, en el sentido de que ambas tienen mejores relaciones con los compañeros que con las compañeras:

- Yo diría que tengo más relación con los hombres que con las mujeres. Me parece que hay más apertura (Mujer 1).

- Yo es que por naturaleza hablo más con hombres y me llevo mejor con los hombres. Son más accesibles. Con las mujeres ha sido más superficial (Mujer 2).

Este es un aspecto que requiere mayor investigación, se debe profundizar por qué algunas mujeres sienten que se relacionan mejor con los hombres que con sus congéneres. Una posible hipótesis es que producto de la socialización las mujeres han interiorizado la sobrevaloración de lo masculino y desvalorización de lo femenino, aspecto que incide directamente en las relaciones con las personas; ya que perciben que los hombres son más accesibles y que pueden confiar más en ellos que en las mujeres.

\section{USO DEL ESPACIO}

Existe una estrecha relación entre los modelos educativos y los modelos espaciales como contenedores sociales de estas actividades, por lo cual se observó y analizó la distribución y uso de los espacios, ya que este también reproduce las relaciones de poder y los modelos de comunicación implícitos en dichas relaciones.

De esta forma se trató de visibilizar cómo están diseñados los espacios educativos (específicamente aulas) en la Universidad de Costa Rica en general, y en la Facultad de Educación, lugar donde se llevó a cabo la observación de la investigación. Ya que de acuerdo con Vásquez (1996, p. 51) los actores que representan la institución (especialmente los maestros, pero también los inspectores y los directores de los establecimientos) no tienen conciencia del efecto que tendrá el escenario que han montado y donde actúan cotidianamente; por lo cual se consideró necesario realizar dicho análisis, como un elemento que determina los procesos comunicativos en el aula.

\subsection{Modelos espaciales funcionalistas}

Después de observar dichos espacios se llega a formular la hipótesis (a ser comprobada con estudios cuantitativos)de que el concepto espacial que se operacionaliza en las diferentes 
construcciones de la Universidad de Costa Rica es el funcionalista, donde se plantea un "tipo" de espacio para la actividad educación, el cual casi siempre es de la misma forma, inflexible, direccional y jerárquico.

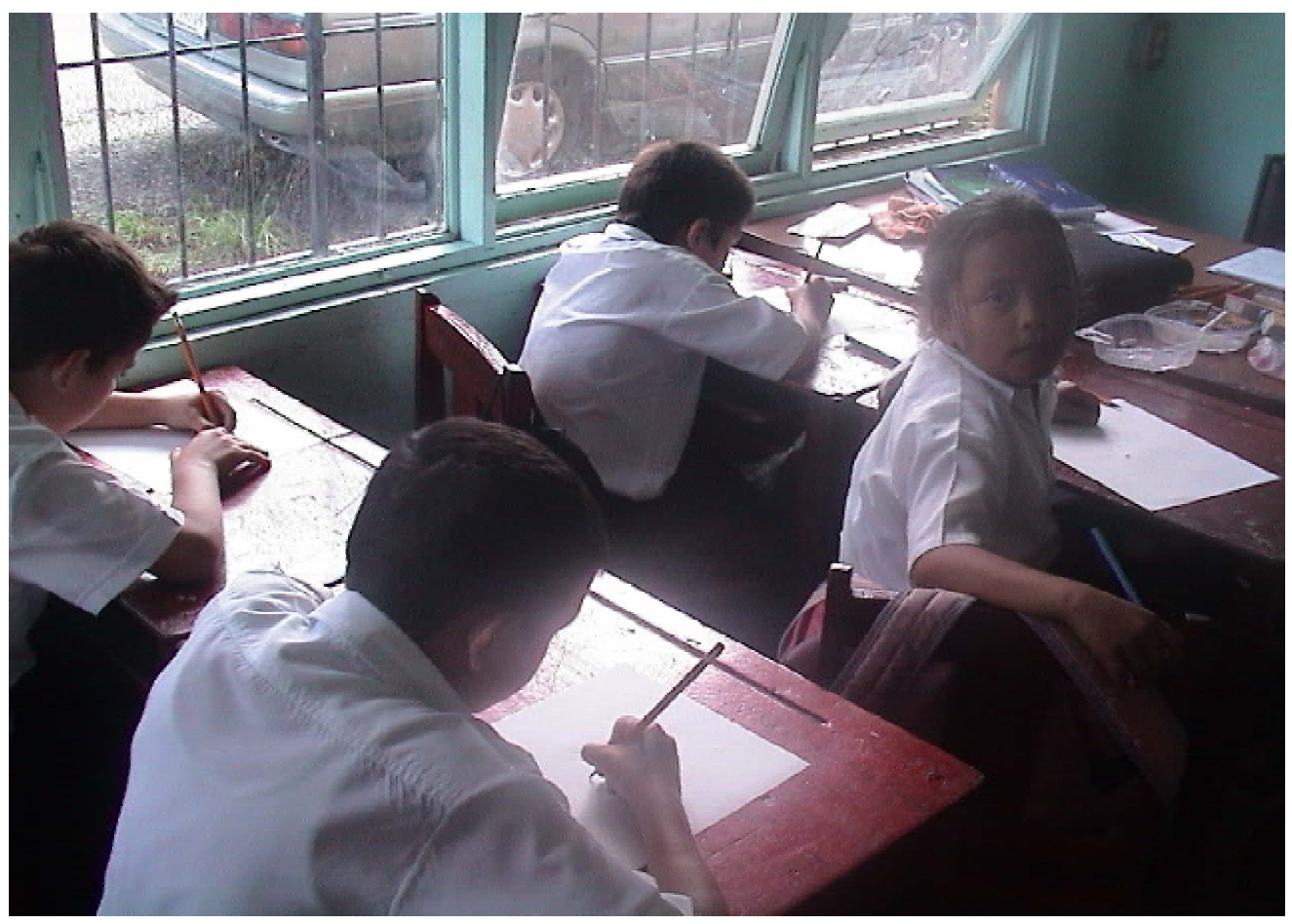

Por eso es que cuando se piensa en un espacio para educación surge la idea de una aula, casi como único tipo de espacio en el cual se pueden dar los procesos educativos formales. Este tipo de aula adquiere variantes básicamente de escala, pero manteniendo su carácter impersonal, abstracto, jerárquico y direccional.

En general la Universidad de Costa Rica y específicamente la Facultad de Educación cuenta con los siguientes espacios de la educación tradicional, según Garnier (1984):

- El aula como clase magistral: no se llevó a cabo la medición de las aulas, pero con la simple observación se puede concluir que casi todas tienen las mismas dimensiones y la misma distribución del espacio: pizarra y escritorio para la persona que asume el rol de docente al frente y pupitres (de una sola pieza) ubicados en filas, con capacidad para 30 o 40 estudiantes. En algunas ocasiones la puerta de entrada está ubicada en el extremo más cercano a la pizarra y escritorio. 
- El auditorio como gran salón para transmisión masiva de información.

- Sala de audiovisuales que no cambian la relación de comunicación autoritaria y jerárquica, presentándose muchas veces como la novedad pedagógica.

\subsection{Incidencia del uso del espacio y el mobiliario en el proceso educativo}

En el curso, la mayoría de las veces se empleó el orden tradicional de filas, aunque en muchas ocasiones se utilizó el aula tal y como estaba, a las 5 p.m., después de un día de actividades. En la primera sesión, que fue en la sala de multimedios, estaba ordenada en filas. La profesora tomó posición cercana a los estudiantes, de pie y al frente. Los técnicos estaban colocando equipo audiovisual.

- Para distribuir temas la profesora se sentó en un pupitre igual al de I@s estudiantes, frente a ellos y ellas.

En algunas ocasiones la profesora pidió formar círculo y trabajar así y una estudiante dijo un día: "cómo me gustó hoy la clase, me gusta más trabajar así" (en círculo y comentando la lectura asignada para ese día, en contraposición de otros días cuando se trabaja en filas y se hacen comprobaciones de lectura).

Al consultarle a la docente sobre la incidencia del diseño del espacio y ubicación del mobiliario en el proceso educativo, ella respondió:

"Pienso que sí, sobre todo que nosotros somos grupos pequeños y en espacios amplios se diluye la atención. Por supuesto que el mobiliario tiene que ver: sillas cómodas. Las aulas grandes dan una sensación de frialdad, poco acogedoras y ellos también están más alejados".

Por su parte las y los estudiantes entrevistados manifestaron:

"Podría ser. Porque no es lo mismo, porque los chiquillos están acostumbrados a estar ubicados en filas de 6 pupitres. Cuando están en círculo son más espontáneos, no son tan rígidos" (Mujer 1). 
"Sí influye la posición, porque no es lo mismo cuando alguien opina al estar en un círculo a cuando está en fila viendo al maestro. Facilitan más la participación (el trabajar en círculo), incluso la disciplina. Además de la teoría, aprenden reglas de socialización, reglas de cómo sentarse” (Mujer 2).

"La diferencia que se da al variar el uso del espacio es en la producción: ellos producen más en los subgrupos que cuando están en clase magistral (se distraen con más facilidad). Para los estudiantes es más fácil el proceso entre ellos, porque hay una competencia sana" (Hombre 1).

"La forma en que se acomode un aula incide en el comportamiento de la gente. El orden en fila se presta para más disciplina, en grupo se arma el desorden. Gente salida de la fila causa interrupción y esto afecta el derecho a los que si quieren aprender. Yo los formo en subgrupos de 5 personas, pero alejados, para que cambie la manera rígida y para que se distraigan de vez en cuando. Siempre lo mismo cansa. A veces yo los saco del aula y producen más. A ellos no les gusta sólo el trabajo en subgrupos, porque tienen que responder guías" (Hombre 2).

Con base en las anteriores afirmaciones podemos afirmar:

- Las personas entrevistadas todas son docentes (de primaria a universidad) y el conversar sobre este tema los hace pensar en este aspecto, o sea que no ha sido abordado en los procesos formativos de ellas, ni es retomado en la práctica educativa cotidiana.

- Tanto la docente del curso como I@s estudiantes entrevistados opinan que el diseño del espacio en el proceso educativo afecta al mismo proceso y entre las formas que incide están: aulas muy grandes para grupos pequeños, hace que se diluya el proceso; estudiantes producen más cuando trabajan en círculo y en subgrupos que en las clases tradicionales.

- En cuanto a disciplina se presentan dos opiniones: una que dicen que el trabajar en círculo mejora la disciplina y otra que dice que el orden en filas se presta para más disciplina. La diferencia se da porque en el primer caso la maestra compara el trabajar en filas con el trabajar en círculo, mientras que en el segundo el profesor compara el trabajar en filas con el trabajar en subgrupos; además, la profesora trabaja con estudiantes de primeros grados de primaria y el segundo con adolescentes. En algunos casos las y los docentes entrevistados utilizan el trabajo en subgrupos conscientemente mientras que en 
otro (Hombre 2) lo utiliza como una forma "para que cambie la manera rígida y para que se distraigan de vez en cuando".

\subsection{Uso del espacio en el curso observado}

En el curso observado, el espacio se utilizó la gran mayoría de las sesiones en filas, en ocasiones desdibujadas por el uso del espacio anterior al curso. Esto es constatado por las y los estudiantes entrevistados:

"Muy reducido, una gran aula y estábamos en un campito todos en el mismo lugar siempre. Casi siempre en fila, muy pocas veces en círculo" (Mujer 1).

"No me pareció, era un espacio muy estático. Se varió como en 2 ocasiones. Hasta yo usaba el mismo lugar, era muy metódico. A como estaban los pupitres, así nos colocábamos. No rompimos filas, si lo hacíamos era para estar con los compañeros de siempre. No hubo esquemas de uso del espacio. La profesora tenía dos posiciones: al frente explicando, o al lado norte/sur, cuando un compañero tenía que exponer" (Hombre 1).

La docente afirmó que un espacio tan grande para un grupo pequeño dificulta el proceso, porque los participantes están alejados. Mientras que las y los estudiantes expresaron que el uso del espacio en el curso, incidió en:

"Por esa dinámica no se dió mucha interacción cuando terminaba la exposición, no se daba el juego de pregunta respuesta. Cuando hubo debate fue forzado porque la profesora hacía las preguntas, por la misma dinámica de que la comunicación fue muy vertical" (Mujer 2).

"No manejar la creatividad para el desarrollo de ciertos temas. Cada uno sabía el compañero o compañera que tenía a la par. Se establecieron códigos no verbales (miradas de aprobación o no de una participación, sonrisas de aprobación o negación de lo que se estaba hablando), no intercambiábamos con otros compañeros" (Hombre 1). 
De lo anterior se puede concluir que el espacio se usaba tal como estaba, a las 5 de la tarde.

- Los y las estudiantes se ubicaban buscando la comodidad o dependiendo de sus intereses variaban un poco el orden.

- La docente permaneció en el frente del aula, lo cual hace evidente las jerarquías. Cuando se realizaban exposiciones por parte de las y los estudiantes, quien exponía se ubicaba al frente, ocupando el lugar destinado para la o el docente del curso y la profesora se ubicaba entre quien exponía y el grupo.

\section{CONCLUSIONES Y RECOMENDACIONES:}

\subsection{Conclusiones:}

- Podemos concluir que la educación continúa en el viejo paradigma, en cuanto a comunicación, ya que según Pearce (1994) el viejo paradigma es en gran medida un paradigma ligado a la divulgación escrita de materiales: su noción acerca del conocimiento requería que aquello que se considerara como tal fuera escrito o pudiera serlo. En el curso observado se constata este hecho, en cuanto a que las actividades se basan en textos, los cuales son expuestos o analizados, pero no se utilizan como materia prima para realizar otras actividades, como las que plantea el construccionismo, por ejemplo.

- Relaciones: En principio los roles de poder (y con ello el tipo de relaciones) determinados por la posición de I@s actor@s en el proceso educativo son desempeñados por las personas indistintamente de su género. Con esto se quiere decir que la persona que asume el rol de docente en el curso tiene el rol de dominación, es quien determina el programa del curso y con ello las reglas del juego de todo el proceso. Y quienes se desempeñan como estudiantes asumen el rol de dependientes o sumisión a la autoridad.

En cuanto a I@s estudiantes, se observó que tod@s asumen el rol de sumisión; sin embargo, los estudiantes varones se desempeñan con mayor determinación y seguridad que sus compañeras, mientras que las mujeres al intervenir hacen comentarios 0 sugerencias, los varones se expresan de una forma más afirmativa, asumiendo así el rol de emisores privilegiados que les es asignado en el proceso de socialización.

En el caso de las mujeres, se observan dos comportamientos: unas (las menos) se desempeñan más afirmativamente, estableciendo diálogos coloquial (tu a tu) con sus 
compañeros y con la docente, mientras que otras (la mayoría) asumen un rol de pasividad, participan sólo cuando se les pregunta y lo hacen con afirmaciones menos determinantes mas relativas; con lo cual desempeñan el rol de sumisión asignado socialmente a las mujeres.

“Las mujeres somos más tranquilas, más pasivas, también eso influye” (Mujer 2).

En general se observó que los hombres se sienten más presionados a participar y decir lo que piensan, mientras que las mujeres no tienen esa presión y a veces deben "pelear" su derecho a expresarse, porque la docente (en general, no siempre) demanda más respuestas de los hombres que de las mujeres.

- El curso observado puede calificarse como representativo en los aspectos que aborda la investigación que origina este artículo. En este sentido se afirma que la UCR es parte y reproductora de la sociedad patriarcal, ya que según Vásquez (1996, p. 42) la institución educativa socializa tanto a los estudiantes como a los docentes y constituye una cultura en el sentido de que está estructurada en torno a un conjunto de valores que le son propios y que actúan globalmente sobre sus miembros contribuyendo a su socialización (tanto de los niños como de los adultos).

Esta afirmación se basa en aspectos como el diseño y uso del espacio en los procesos educativos y en el diseño de los programas de los cursos y con todo ello en el tipo de relaciones de poder que se establecen entre docentes y estudiantes.

- El lenguaje empleado tanto en los documentos (programa, texto del curso, perfil profesional, etc.) como en las clases es sexista, se emplea el genérico de hombre.

\subsection{Recomendaciones:}

- Realizar investigaciones que validen los hallazgos y datos de esta investigación en otras unidades académicas de la institución y del sector educativo.

- Confrontar los resultados de esta investigación con personal docente y administrativo de los diferentes niveles jerárquicos de la institución, como parte del proceso de construcción de la equidad de género que se ha planteado. 
- Promover procesos educativos en los cuales se desarrollen procesos comunicativos con equidad: en cuanto a lenguaje que sea inclusivo; relaciones de cooperación, apoyo, solidaridad, equidad y que el uso del espacio facilite y promueva relaciones equitativas entre las personas que participan en estos procesos.

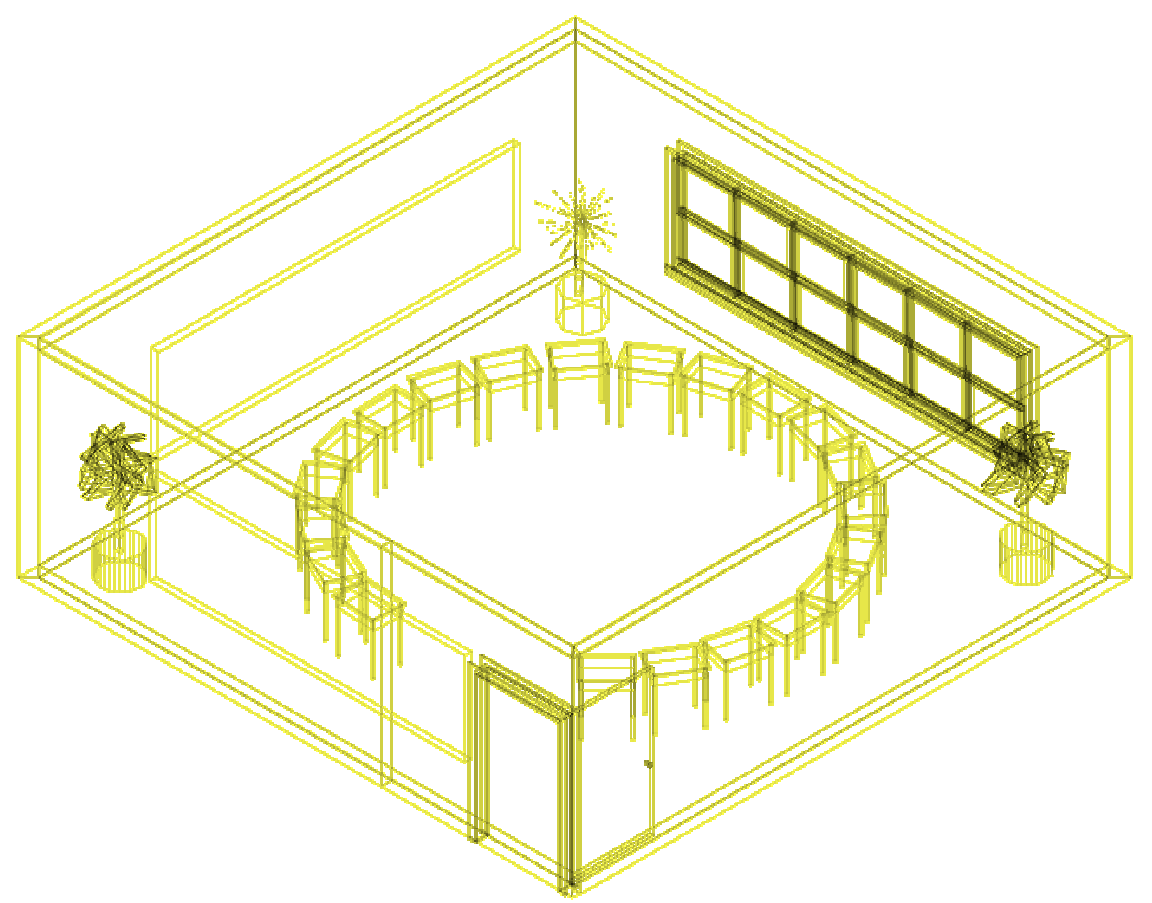

Para aquellas personas que trabajen en la docencia y les interese aplicar aspectos de la presente investigación, pueden iniciar un proceso en ese sentido respondiéndose interrogantes como:

- ¿En cuál modelo educativo me ubico en la mayoría de las actividades que realizo en el aula?

- ¿Cuáles y cómo son las relaciones que establezco con I@s estudiantes?

- ¿Me gustaría variar este tipo de relaciones?

- ¿En qué actividades del proceso educativo puedo variar el uso del espacio y la distribución del mobiliario?

- ¿Cuál es el uso del lenguaje que hago en el curso? 


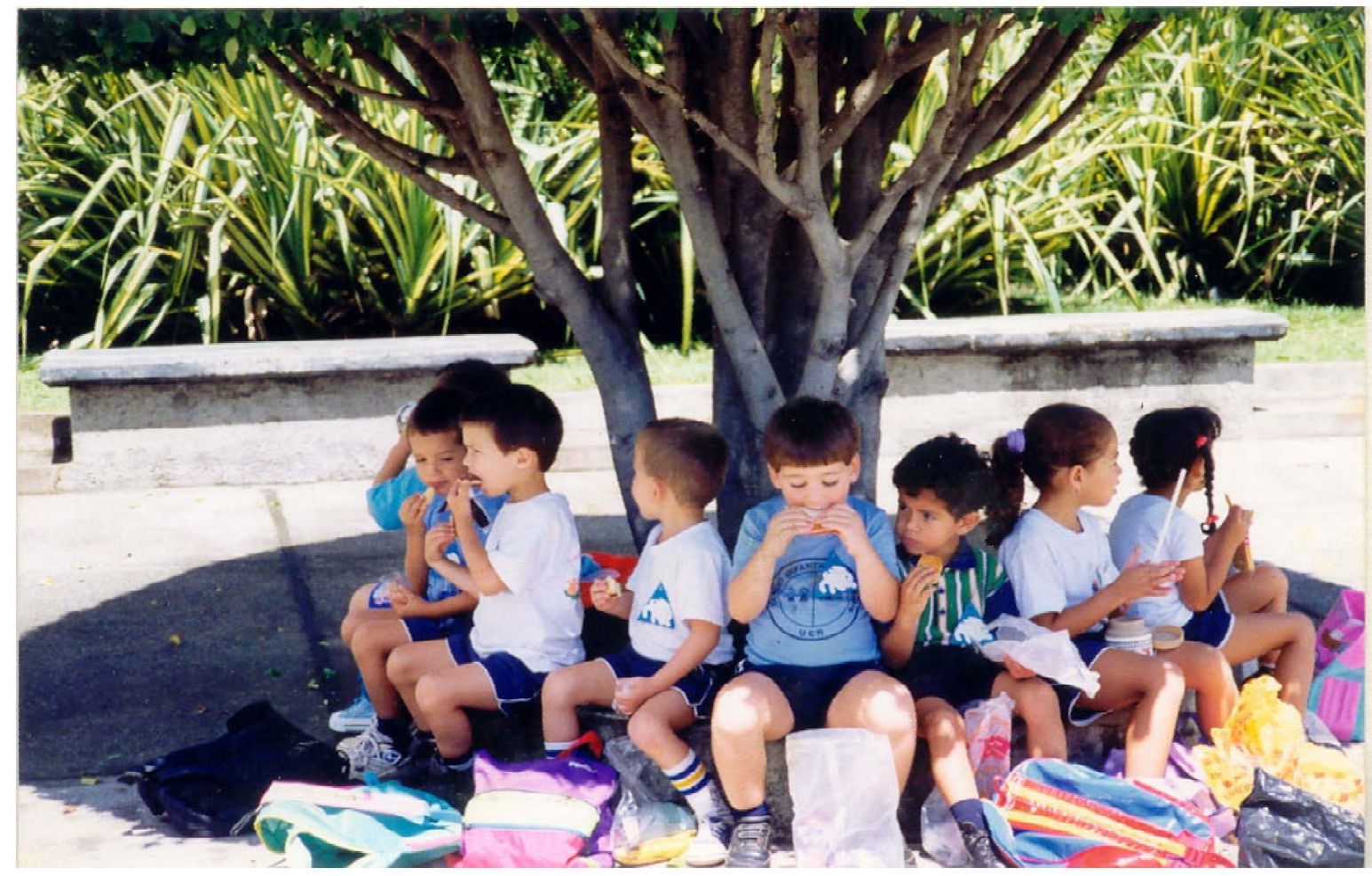

\section{REFERENCIAS}

Abramovay, Miriam. (1994). Sexo y Género. En: Programa Interdisciplinario de Estudios de Género. Introducción al análisis de género (categorías analíticas básicas). Managua: UCA.

Alexander. Christopher. (1983). Urbanismo y Participación. Colección Punto y Línea. Barcelona: Editorial Gustavo Gili.

Bourdieu, Pierre y Paseeron, Jean Claude. (1970). La reproducción. Elementos para una teoría del sistema de enseñanza. Barcelona, España: Editorial laia.

Calero Fernández, Ma. Ángeles. (1999). Sexismo lingüístico. Análisis y propuestas ante la discriminación sexual en el lenguaje. Madrid, España: Narcea, S. A. de Ediciones.

Camacho, J. A. y Pardo, M. E. (1994). Etnografía, epistemología y cualidad. En Reflexiones $\mathbf{N}^{\circ}$ 27. Facultad de Ciencias Sociales. Universidad de Costa Rica.

Coll, César; Martín, Elena y otros. (1997). El constructivismo en el aula. Barcelona, España: Editorial Graó. 
Díaz Bordenave, Juan. (1976). Las nuevas pedagogías y tecnologías de comunicación. Ponencia presentada a la Reunión de Consulta sobre la Investigación para el Desarrollo Rural en Latinoamérica. Cali, Colombia.

Escalante, Ana Cecilia. (1996). Propuesta de investigación-acción: género, mujeres y políticas en el Gran Caribe. Coordinadora Regional de Investigaciones Económicas y Sociales (CRIES). Taller Regional. Costa Rica.

Facio Montejo, Alda. (1994). Cuando el género suena cambios trae. En: Programa Interdisciplinario de Estudios de Género. Introducción a los estudios de género: categorías básicas de análisis y el sistema sexo-género, como expresión de relaciones de poder. Lecturas 1. Managua, Nicaragua: Universidad Centroamericana.

Freire, Paulo. (1998). Pedagogía de la esperanza. México: Siglo XXI.

Gallegos, Nava, Ramón. (1999). Educación holista. Pedagogía del amor universal. México: Editorial Pax.

Garnier, José Enrique. (1984). Proyectos de los Centros Académicos de la UNED. Tesis de grado para Licenciatura en Arquitectura U.C.R. Costa Rica.

Izquierdo, Ma. Jesús. (1991). Un marco teórico para las relaciones de sexo y de género. En: Luna, Lola (Comp.) Mujeres y Sociedad. Nuevos enfoques teóricos y metodológicos. Universitat de Barcelona, España.

Kaplún, Mario. (1985). El comunicador popular. Quito, Ecuador: Editorial Belén.

Mañeru Méndez, Ana. (1991). Lenguaje en la escuela: sexismo en el lenguaje. En: Infancia y sociedad. Revista de Estudios No. 10. Julio- Agosto. España: Ministerio de Asuntos Sociales.

Miranda, Nelly. (1994). El sistema sexo-género con dominación masculina: análisis de la situación marginal de la mujer nicaragüense. En: Programa Interdisciplinario de Estudios de Género. Introducción al análisis de género (categorías analíticas básicas). Managua: UCA.

Pearce, Barnett. (1994). Nuevos modelos y metáforas comunicacionales: el pasaje de la teoría a la praxis, del objetivismo al construccionismo social y de la representación a la reflexividad. En: Fried S., Dora. Nuevos paradigmas, cultura y subjetividad. Argentina: Paidós.

Prieto, Daniel. (1985). Diagnóstico de comunicación. Manuales didácticos CIESPAL \#10. Quito, Ecuador: Editorial Belén.

Racionero, Luis. (1978). Sistemas de ciudades y ordenación del territorio. Madrid: Alianza Editorial.

Taylor, S. J. y Bogdan, R. (1992). Introducción a los métodos cualitativos de investigación. España: Ediciones Paidós. 
Vásquez B, Ana. Martínez, Isabel. (1996). La socialización en la escuela. Una perspectiva etnográfica. España: Paidós.

Villarreal, Ana Lucía. (1999). Relaciones de poder. Mujeres en la encrucijada entre trabajo productivo y trabajo reproductivo. Tesis de Maestría en Sociología, Universidad de Costa Rica.

Villarreal, Ana Lucía y Garnier, José Enrique. (1995-1996). La comunicación y el espacio en los procesos educativos. En: Revista Herencia. Volumen 7, No. 2 y Volumen 8, No. 1. Vicerrectoría de Acción Social, Universidad de Costa Rica. 